\title{
Use of the somatostatin analogue octreotide to localise and manage somatostatin-producing
}

\section{tumours}

S Angeletti, V D Corleto, O Schillaci, M Marignani, B Annibale, A Moretti, G Silecchia, F Scopinaro, N Basso, C Bordi, G Delle Fave

\begin{abstract}
Background-Somatostatin receptor scintigraphy (SRS) and octreotide therapy have both changed the management of gastroenteropancreatic endocrine tumours, but very few data are available on the use of SRS and octreotide to visualise and treat somatostatinomas.

Method-The results of SRS and octreotide treatment in three somatostatinoma patients were examined.

Results-SRS was able to detect extensive hepatic involvement in patient 1 , one hepatic and one pancreatic lesion in patient 2 , and one hepatic lesion in patient 3. Octreotide therapy $(0.5 \mathrm{mg} / \mathrm{day}$ subcutaneously) was effective in decreasing plasma levels of somatostatin in all three patients. Symptoms (diabetes and diarrhoea) were greatly improved in the two patients with "somatostatinoma syndrome".

Conclusion-The study shows that somatostatinoma, like most other gastroenteropancreatic endocrine tumours, possesses functioning somatostatin receptors. (Gut 1998;42:792-794)
\end{abstract}

Department of Gastroenterology, University "La Sapienza", Rome, Italy $S$ Angeletti

V D Corleto

M Marignani

B Annibale

A Moretti

G Delle Fave

Department of Nuclear Medicine

O Schillaci

F Scopinaro

Department of

Surgery

G Silecchia

N Basso

Department of Pathology, University of Parma, Parma, Italy C Bordi

Correspondence to: Dr G Delle Fave, Cattedra di Gastroenterologia I, Clinica Medica 2, Policlinico Umberto I ${ }^{\circ}, 00161$ Roma, Italy.

Accepted for publication 19 January 1998

(SS)-producing tumour; fewer than cases have been described ${ }^{12}$ accounting for less than $1 \%$ of all gut and pancreatic endocrine tumours. Some $75 \%$ of somatostatinomas are localised in the pancreas, and most nonpancreatic tumours are found in the duodenum and jejunum. ${ }^{23}$ Overall, more than $85 \%$ of the cases have displayed metastases, located mainly in the liver and lymph nodes. The first cases reported were found by accident, and the diagnosis of somatostatinoma is generally based on postoperative histological evaluation. Preoperative diagnosis of a somatostatinoma remains difficult because the so called "somatostatinoma syndrome" (diabetes mellitus, gallbladder disease, diarrhoea, and weight loss) actually produces non-specific symptoms. ${ }^{4}$ Furthermore, for unknown reasons, the syndrome occurs only in the pancreas; the duodenal location of primary tumour is apparently associated with "local discomfort" or is completely symptom-free. The histological characteristics of pancreatic somatostatinomas are indistinguishable from those of other pancreatic endocrine tumours. The diagnosis is therefore established by immunocytochemical examination of the resected tissue with typical endocrine tumour features and a predominant or pure population of " $\mathrm{D}$ " cells. Often a significantly increased concentration of SS-like immunoreactivity in the plasma and/or tumoral extracts further supports the diagnosis of somatostatinoma in many studies. ${ }^{1-4}$

Over the last few years, octreotide, a synthetic SS analogue, has drawn a lot of attention mainly because of its antisecretory and antiproliferative effects on SS receptor bearing tumours. ${ }^{5}$ Recently a modified analogue of octreotide, labelled with indium 111 (Octreoscan), has been used to localise SS receptor positive tumours in vivo. ${ }^{67}$ To our knowledge, very few data $^{8}$ are available on octreotide treatment of somatostatinoma and/or tumour lesion detection with Octreoscan, although it is known that the " $D$ " cells possess SS receptors. ${ }^{9}$ In the present study we report on three patients with SS-producing tumour (two pancreatic, one duodenal), treated long term with octreotide after evaluation of SS receptor status using SS receptor scintigraphy (SRS).

\section{Patients}

Fifty two consecutive patients referred to our unit with a diagnosis of a gastroenteropancreatic tumour were evaluated for somatostatinomas. In three of the patients, a somatostatinoma was diagnosed on the basis of high basal circulating levels of SS, increased " $D$ " cell number in tumour tissue specimens, and, in two of them, the presence of somatostatinoma syndrome (table 1).

\begin{tabular}{lllllllll} 
Table 1 & Clinical and biochemical data of the three patients with somatostatinoma \\
\hline \multicolumn{1}{l}{ Age $(y)$} & Sex & Gallstone disease & $\begin{array}{l}\text { Diabetes type } \\
\text { II }\end{array}$ & Diarrhoea & Weight loss & SS (pg/ml) & NSE (g/l) \\
\hline Patient 1 & 75 & F & Yes & Yes & Yes & No & 67.5 & 22 \\
Patient 2 & 61 & F & Yes & Yes & Yes & Yes & 65 & 24 \\
Patient 3 & 60 & M & Yes (sludge) & No & No & No & 200 & 32 \\
\hline
\end{tabular}

SS, somatostatin; NSE, neurone specific enolase. Normal values: SS $<25$ pg/ml; NSE $<12$ g/l. 
Table 2 Localisation and number of somatostatinoma lesions visualised by $\left[{ }^{11} I n\right]$ Octreoscan scintigraphy (SRS) and computed tomography (CT) scan in the three patients with somatostatinoma

\begin{tabular}{|c|c|c|c|c|}
\hline \multirow[b]{2}{*}{ Patient 1} & \multicolumn{2}{|l|}{ SRS (SPECT) } & \multicolumn{2}{|l|}{ CT scan } \\
\hline & Pancreas & 1 lesion & Pancreas & 1 lesion \\
\hline & Liver & $\begin{array}{l}\text { Multiple } \\
\text { metastases }\end{array}$ & Liver & $\begin{array}{l}\text { Multiple } \\
\text { metastases }\end{array}$ \\
\hline & Lung & 2 lesions & Lung & 2 lesions \\
\hline & Mediastinum & 2 lesions & Mediastinum & Negative \\
\hline \multirow{2}{*}{ Patient 2} & Liver & 1 lesion & Liver & 1 lesion \\
\hline & Pancreas & 1 lesion & Pancreas & 1 lesion \\
\hline Patient 3 & Liver & 1 lesion & Liver & Negative \\
\hline
\end{tabular}

PATIENT 1

A 75 year old woman was admitted to the hospital in poor general condition with type II diabetes, gallbladder stones, and mild diarrhoea. Abdominal ultrasound showed numerous liver nodular lesions and multiple gallbladder stones. Computed tomography (CT) scan confirmed extensive hepatic involvement and in addition showed an enlargement of the pancreas and two additional lesions located in the apices of both lungs (table 2). Basal plasma levels of SS were elevated as well as serum neurone specific enolase (NSE) (table 1). Histological examination of an hepatic nodule needle biopsy specimen showed features of a well differentiated pancreatic endocrine tumour. Diffuse SS and NSE immunoreactivity was clearly observed. SRS visualised multiple hepatic localisations, pancreatic body and lung lesions, and two additional lesions in the lower mediastinum (table 2). Owing to the extensive tumoral localisation and the generally poor condition of the patient, no surgical procedure was performed. Octreotide treatment (0.5 $\mathrm{mg}$ /day subcutaneously) was started.

PATIENT 2

A 61 year old woman was hospitalised as the result of the sudden development of type II diabetes, diarrhoea, and moderate weight loss (9 $\mathrm{kg}$ over the preceding six months). She reported that gallbladder stones had been diagnosed within the previous year. On admission, stool weight was 605 g per day with an elevated amount of fat ( $21 \mathrm{~g} /$ day). Basal plasma levels of SS were increased as well as serum

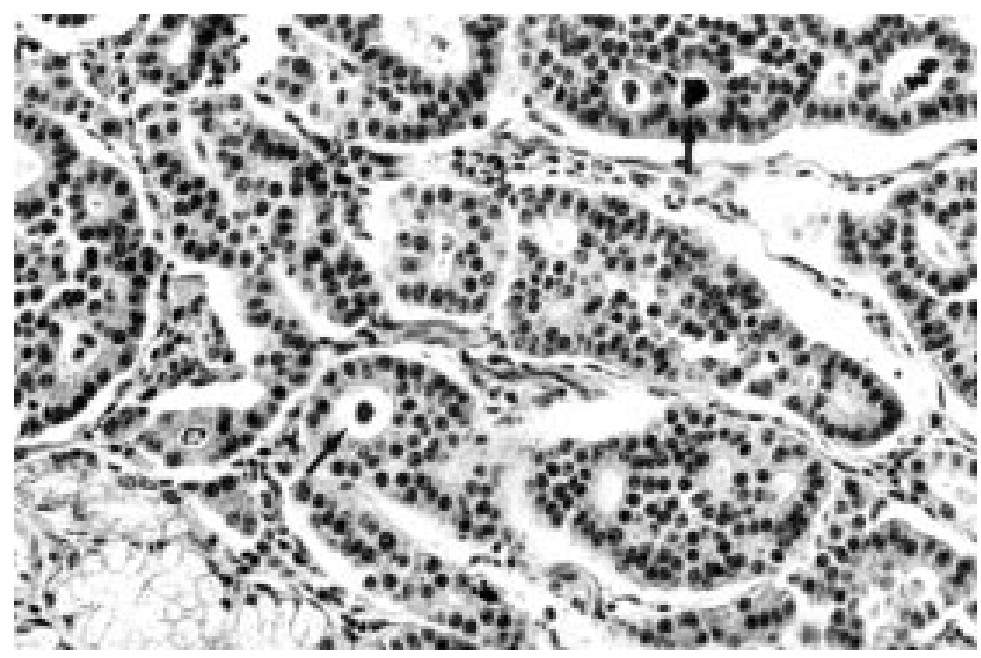

Figure 1 Histological appearance of duodenal somatostatinoma of patient 3 showing numerous gland-like structures often with psammoma bodies in the lumen (arrows) (haematoxylin and eosin stain; original magnification $\times 265$ ).
NSE (table 1). Abdominal ultrasound showed a mass in the tail of the pancreas (diameter 4 $\mathrm{cm}$ ) and another nodule in the liver. All these findings were further confirmed by CT scan (table 2). Histological examination of a liver biopsy specimen showed typical structures of a pancreatic endocrine tumour consistent with a pancreatic primary. Immunocytochemical staining showed diffuse positivity for SS and NSE. SRS confirmed the number and location of the tumoral lesions visualised by CT scan (table 2). The patient refused surgery, and treatment with octreotide $(0.5 \mathrm{mg} /$ day subcutaneously) was initiated.

\section{PATIENT 3}

A 60 year old man was referred to us after having undergone pancreatic duodenectomy (Whipple procedure) to remove a $4.6 \times 3.3 \mathrm{~cm}$ head of pancreas mass and a parietal nodule of the second portion of the duodenum. The histological appearance of the tumour was typical of a duodenal somatostatinoma, showing an endocrine tumour with numerous glandular structures often with a psammoma body in the lumen (fig 1). The tumour, originating from the duodenal mucosa, was extensively infiltrating the underlying muscular wall and the contiguous pancreatic region. On immunocytochemistry, virtually all tumour cells exhibited intense immunostaining for SS (fig 1).

On admission, the patient was in good general condition and reported no specific symptoms. Plasma levels of SS and NSE were considerably elevated (table 1). Abdominal ultrasound showed gallbladder sludge with microstones, and a CT scan showed no tumoral lesions (table 2). SRS showed an area of intense uptake in the left lobe of the liver (table 2). Octreotide treatment $(0.5 \mathrm{mg} /$ day subcutaneously) was started. After one year, another SRS evaluation was performed, which showed that the previous hepatic lesion had not changed. Subsequent surgical laparotomy was performed and three tumoral lesions were removed from the liver. One of them $(3 \mathrm{~cm}$ diameter) was found in the area of SRS positivity (left hepatic lobe). The two other lesions, not visualised by SRS, were both less than $1 \mathrm{~cm}$ in diameter and localised in the right hepatic lobe. Immunocytochemical staining was strongly positive for SS in all three of the resected tumoral lesions, but no psammoma bodies were present.

CLINICAL AND BIOCHEMICAL FOLLOW UP

The diabetes and diarrhoea in patient 1 and the diabetes, diarrhoea, and weight loss in patient 2 were improved after six months of octreotide treatment and remained improved at the one year evaluation. Octreotide therapy was effective in progressively decreasing plasma levels of SS in all three patients by $40-80 \%$ after one year.

\section{Discussion}

This study describes three patients with a gastroenteropancreatic endocrine tumour according to all diagnostic criteria (clinical, biochemical, and histological) for defining an 
SS-producing tumour. Furthermore, this study suggests that somatostatinoma tumour tissue possesses functioning SS receptors. This suggestion is supported by the ability of ${ }^{111} \mathrm{In}$ Octreoscan scintigraphy to detect somatostatinoma tumour lesions in all three patients studied and by the effectiveness of octreotide in reducing circulating levels of SS and controlling related symptoms both in primary and/or metastatic somatostatinoma patients.

Previous studies, using in vitro and in vivo binding techniques, have shown the presence of SS receptors in $80 \%$ of the gastroenteropancreatic endocrine tumours. ${ }^{10}$ Few data are available on evaluation in vivo of SS receptors in somatostatinoma tumour tissue..$^{11}{ }^{11}$ In one case, treatment with octreotide did not reduce comparatively high circulating SS levels possibly because of receptor tachyphylaxis, as suggested by the authors. ${ }^{8}$

In the present study, an octreotide-like compound was able to bind and visualise the SS receptors expressed by somatostatinoma tumour tissues in patients with abnormally high plasma levels of SS, and therefore the high SS levels cannot be the cause of the false negative results. There are various possible explanations for these data. Firstly, the circulating SS levels may not be high enough to interfere with binding of the SS analogue; moreover octreotide may have a higher affinity for tumoral SS receptors than the circulating SS. Secondly, the tumour may produce forms of SS that are not biologically active-for instance, prohormones - and enzymic degradation may affect natural SS but not synthetic SS analogues. $^{12}$ Furthermore, octreotide treatment was effective in reducing plasma levels of SS and related symptoms in the two patients with the syndrome, whereas, in patient 3, SRS failed to visualise two of the three immunohistochemically proven hepatic somatostatinoma lesions, suggesting the presence of a different SS receptor subtype pattern on some (the ones that gave negative results on scintigraphy) metastatic lesions. ${ }^{13}$

It has also been reported that injection of tolbutamide or calcium/pentagastrin is able to stimulate SS secretion only in somatostatinoma patients with normal basal levels of SS and not in normal controls. ${ }^{14}$ We did not try any stimulation tests as our patients had elevated basal SS levels.

Although the reasons for the false negative SRS results for patient 3 are not known, as previously reported, differences in blood supply ${ }^{15}$ and locally high concentrations of endogenous SS with alterations in receptor function have been reported to play an important role in SRS false negative gastroenteropancreatic endocrine tumour visualisation. Our data indicate that SRS, a non-invasive diagnostic procedure, is able successfully to localise primary and metastatic somatostatinoma tumours. Our results suggest that ${ }^{111}$ In-pentetreotide-SPECT, as shown for other gastroenteropancreatic endocrine tumours, ${ }^{7}$ may be a useful early diagnostic technique for accurately staging tumour extension in patients with somatostatinoma. Moreover, because of its ability to visualise SS receptors in vivo, SRS is a useful tool for selecting those patients with somatostatinoma syndrome who will benefit from octreotide treatment.

This work was supported by grant No 02/12/01/10, 1994-1995, from the Italian Ministry for the University (MURST). We also thank ByK Gulden Italia for generously supplying Octreoscan.

1 Jensen RT, Norton JA. Endocrine tumors of the pancreas. In: Sleisenger MH, Fordtran JS, eds. Gastrointestinal disease: pathophysiology/diagnosis/management. Philadelphia: WB Saunders, 1993;2:1695-721.

2 Konomi K, Chijiiwa K, Katsuta T, et al. Pancreatic somatostatinoma: a case report and review of the literature. f Surg Oncol 1990;43:259-65.

3 Bordi C, D'Adda T, Azzoni C, et al. The somatostatin cell. Progress in Basic Clinical Pharmacology 1996;10:2-22.

4 Sassolas G, Chayvialle JA. GRFomas, Somatostatinomas: clinical presentation, diagnosis, and advances in management. Frontiers in Gastrointestinal Research 1995;23:194207.

5 Arnold R, Trautmann ME, Creutzfeld W, et al. Somatostatin analogue octreotide and inhibition of tumour growth in metastatic endocrine gastroenteropancreatic tumours. Gut 1996;38:430-8.

6 Corleto VD, Scopinaro F, Angeletti S, et al. Somatostatin eceptor localization of pancreatic endocrine tumors. World f Surg 1996; 20:241-4

7 Bakker WH, Alberts R, Bruns C, et al. "111 In-DTPA-DPhe1"-octreotide, a potential radiopharmaceutical for imaging of somatostatin receptor-positive tumors: synthesis, radiolabeling and in vitro validation. Life Sci 1991;49: 1583-91.

8 Davis TME, Bray G, Domin J, et al. A case of somatostatinoma: to food and SMS 201-995 administration. Pancreas 1988;3:729-33.

9 Reubi JC, Lamberts SWJ, Maurer R. Somatostatin receptors in normal and tumoral tissue. Horm Res 1988;29:65-9.

10 Reubi JC. Neuropeptide receptors in health and disease: the molecular basis for in vivo imaging. $f$ Nucl Med 1995;36:1825-35.

11 Reubi JC, Waser B, Lamberts SWG, et al. Somatostatin (SRIH) messenger ribonucleic acid expression in human neuroendocrine and brain tumors using in situ hybridization histochemistry: comparison with SRIH receptor content. F Clin Endocrinol Metab 1993;76:642-7.

12 Corleto VD, Severi C, Coy DH, et al. Colonic smooth muscle cells possess a different subtype of somatostatin receptor from gastric smooth muscle cells. Am $\mathcal{F}$ Physiol 1997;272:G689-97.

13 Kubota A, Yamada Y, Kagimoto S, et al. Identification of somatostatin receptor subtypes and an implication for the efficacy of somatostatin analogue SMS 201-995 in treatment of human endocrine tumors. F Clin Invest 1994; 93:1321-5.

14 Pipeleers D, Couturier E, Gepts W, et al. Five cases of somatostatinoma; clinical heterogeneity and diagnostic usefulness of basal and tolbutamide-induced hypersomatousefulness of $\mathcal{F}$ Clin Endocrinol Metab 1983;56:1236-42.

15 John M, Meyerhof W, Richter D, et al. Positive somatostatin receptor scintigraphy correlates with the presence of somatostatin receptor subtype 2. Gut 1996;38:33-9. 